\title{
Investigation of the opioid system in absence seizures with positron emission tomography
}

\author{
Peter A Bartenstein, John S Duncan, Martin C Prevett, Vincent J Cunningham, \\ David R Fish, Anthony K P Jones, Sajinder K Luthra, Guy V Sawle, David J Brooks
}

\begin{abstract}
The neuroanatomical and pathophysiological basis of primary generalised absences is uncertain. Administration of endogenous opioids has been shown to result in absence-like seizures in animal models. Positron emission tomography scans were performed in eight patients with primary generalised epilepsy and eight control subjects. Regional cerebral blood flow was measured interictally with $\mathrm{C}^{15} \mathrm{O}_{2}$, after which a 90 minute dynamic study with the opioid-receptor ligand ${ }^{11} \mathrm{C}$-diprenorphine was performed. Serial absences were precipitated by hyperventilation for 10 minutes, starting 30-40 minutes after injection of diprenorphine. Absences, with generalised spike-wave discharges on the EEG, occurred for between $10 \%$ and $51 \%$ of the provocation period. No individual (normal or patient) had any interictal focal abnormalities of cerebral blood flow. After provocation of serial absence seizures, there was increased diprenorphine elimination from the association cortex, but not from the thalamus, basal ganglia, or cerebellum, compared with control subjects and patients scanned without provocation of absences. It was possible to simulate the observed increased diprenorphine elimination following seizures in cerebral cortex using a two tissue compartment model, with an estimated $15-41 \%$ decrease in the specific tracer uptake rate constant $\left(k_{3}\right)$. These results suggest that endogenous opioids are released in the association cortex at the time of serial absences, lead to increased receptor occupancy, and may have an important role in the pathophysiology of generalised absences.
\end{abstract}

(F Neurol Neurosurg Psychiatry 1993;56:1295-1302)

The neurochemical mechanisms and the anatomical sites involved in the genesis, propagation, and termination of primary generalised seizures are uncertain. Possibilities for the anatomical substrate include occult cortical foci, a diffuse cortical abnormality, and a subcortical focus that drives epileptic activity in the cerebral hemispheres, with involvement of a thalamocortical loop. ${ }^{1-4}$ There is controversy regarding the role of endogenous opioids in the genesis of partial and tonic-clonic seizures, but there is a considerable body of evidence that opioids are released at the time of such seizures and may exert an antiepileptic effect and contribute to post-ictal depression and a rise in seizure threshold. ${ }^{5-9}$ In contrast, absence-like seizures may be provoked by the administration of endogenous and exogenous opioids, and prevented by anti-absence medication and opiate antagonists, implicating a role for endogenous opioids in the genesis of generalised absences. ${ }^{10-13}$

It has been shown that endogenous opioids can displace ${ }^{3} \mathrm{H}$-diprenorphine, a synthetic $\mu$, $\kappa$ and $\delta$ opioid receptor ligand, in hippocampal slices. ${ }^{14} \mathrm{We}$ wished to test the hypothesis that endogenous opioids are released at the time of serial absence seizures in the brain, in humans. We used the synthetic opioid ligand ${ }^{11} \mathrm{C}$-diprenorphine to label cerebral opioid receptors reversibly in vivo and then induced serial absence seizures in patients by hyperventilation, while monitoring diprenorphine binding with positron emission tomography (PET). This allowed us to investigate acute peri-ictal changes in cerebral opioid receptor occupancy. ${ }^{15-19}$

\section{Methods}

PATIENTS

We studied eight patients (five female, three male) with childhood or juvenile absence epilepsy that had not remitted. Their ages ranged from 20 to 49 years (median 32), median weight $62.5 \mathrm{~kg}$ (range: 44-81). Eight male normal volunteers aged between 20 and 41 years (median 34 ), median weight $72 \mathrm{~kg}$ (range: 61-90), were also scanned (table 1). Data on two further patients were not analysed because of movement artefact. All patients were on stable medication, had absence seizures every day and could reliably provoke serial absences by hyperventilation. All patients had normal MRI scans. Five patients (numbers 4-8) were restudied interictally, without provocation of serial absences by hyperventilation.

Permission to perform these studies was granted by the Ethics Committees of the National Hospital for Neurology and Neurosurgery and the Royal Postgraduate Medical School, Hammersmith Hospital, London. Approval to administer radiolabelled gases and ligands was obtained from the Administration of Radioactive Substances Advisory Committee of the United Kingdom (ARSAC). All patients and volunteers gave informed written consent after a full explanation of the procedures. 
Table 1 Characteristics of patients and control subjects

\begin{tabular}{|c|c|c|c|c|c|c|c|}
\hline No & $\begin{array}{l}\text { Sexlage } \\
\text { (years) }\end{array}$ & Diagnosis & $\begin{array}{l}\text { Duration of epilepsy } \\
\text { (years) }\end{array}$ & $\begin{array}{l}\text { Medication } \\
\text { (total daily } \\
\text { dose, } \mathrm{mg} \text { ) }\end{array}$ & $\begin{array}{l}E E G: \\
\% S p W^{\star}\end{array}$ & $\begin{array}{l}\text { EEG: } \\
\% \text { SpW† }\end{array}$ & $\begin{array}{l}\text { Absence induction } \\
\text { period (minutes) }\end{array}$ \\
\hline $\begin{array}{l}1 \\
2\end{array}$ & $\begin{array}{l}\text { F } 23 \\
\text { F } 20\end{array}$ & $\begin{array}{l}\text { JAE } \\
\text { CAE }\end{array}$ & $\begin{array}{l}12 \\
13\end{array}$ & $\begin{array}{l}\text { PHT } 400 \\
\text { PHT } 300 \\
\text { ESM } 1500\end{array}$ & $\begin{array}{l}0.5 \\
1.7\end{array}$ & $\begin{array}{l}23 \\
39\end{array}$ & $\begin{array}{l}40-50 \\
40-50\end{array}$ \\
\hline $\begin{array}{l}3 \\
4 \\
5\end{array}$ & $\begin{array}{l}\text { M 49 } \\
\text { F 41 } \\
\text { F 25 }\end{array}$ & $\begin{array}{l}\text { CAE } \\
\text { JAE } \\
\text { JAE }\end{array}$ & $\begin{array}{l}40 \\
21 \\
13\end{array}$ & $\begin{array}{l}\text { VPA } 2000 \\
\text { VPA } 1500 \\
\text { CBZ } 900 \\
\text { CLOB } 10\end{array}$ & $\begin{array}{l}0.4 \\
1.8 \\
0.7\end{array}$ & $\begin{array}{l}35 \\
29 \\
41\end{array}$ & $\begin{array}{l}40-50 \\
30-40 \\
30-40\end{array}$ \\
\hline 6 & F 20 & CAE & 12 & $\begin{array}{l}\text { ESM } 750 \\
\text { VPA } 2000\end{array}$ & $0 \cdot 3$ & 10 & $30-40$ \\
\hline $\begin{array}{l}7 \\
8\end{array}$ & $\begin{array}{l}\text { M } 32 \\
\text { M } 32\end{array}$ & $\begin{array}{l}\text { JAE } \\
\text { CAE }\end{array}$ & $\begin{array}{l}17 \\
24\end{array}$ & $\begin{array}{l}\text { CBZ } 800 \\
\text { VPA } 1500\end{array}$ & $\begin{array}{l}7 \cdot 0 \\
0 \cdot 7\end{array}$ & $\begin{array}{l}51 \\
41\end{array}$ & $\begin{array}{l}30-40 \\
30-40\end{array}$ \\
\hline
\end{tabular}

$\star$ Before activation period. $†$ During activation period.

\% SpW: Percentage time occupied by absences. CBZ Carbamazepine; CLOB Clobazam.

\section{SCANNING PROCEDURE}

Scans were performed on a high resolution PET scanner (CTI 931/12/8, CTI, Knoxville, TN, USA), the performance characteristics of which have been previously described by Spinks et al. ${ }^{20}$ The final image resolution of this system for 15 simultaneously acquired slices is $8.5 \times 8.5 \times 7.0 \mathrm{~mm}$ (at full width half maximum). Subjects were positioned with the glabella-inion line parallel to the detector-rings so that the intercommisural line (AC-PC line) was in the plane of the directly obtained transaxial images. To minimise movement during scanning, the subject's head was placed in an individually moulded thermoplastic head support. In addition, continual direct observation of the alignment of marks put on the skin to projected crossed laser lines, and video subtraction with live reference to a frozen baseline image were performed.

A 22 gauge arterial cannula was inserted into the radial artery after subcutaneous infiltration with $1 \%$ bupivacaine. The EEG was monitored continuously in all subjects with an eight channel Siemens Mingograph instrument using the $10 / 20$ system of electrode placement. A 10 minute transmission scan was collected using a retractable ${ }^{68} \mathrm{Ga} /{ }^{68} \mathrm{Ge}$ ring source. Cerebral blood flow was measured interictally with $\mathrm{C}^{15} \mathrm{O}_{2}$ (inhalation for two minutes $(6 \mathrm{MBq} / \mathrm{ml})$ ) and a three minute scan composed of 20 frames.

Diprenorphine was labelled with ${ }^{11} \mathrm{C}$ in the O-methyl group using ${ }^{11} \mathrm{C}$-iodomethane. ${ }^{21}$ After decay of $\mathrm{C}^{15} \mathrm{O}_{2}, 300-500 \mathrm{MBq}$ of ${ }^{11} \mathrm{C}$ diprenorphine were injected intravenously over $30 \mathrm{~s}$ and 26 scans were collected over 90 minutes. The median injected dose of the administered tracer was $353 \mathrm{MBq}$ (range: $312-485)$ for the patients and $383 \mathrm{MBq}$ (range: 307-449) for the normal subjects. The median specific activity of the tracer was $13400 \mathrm{MBq} / \mu \mathrm{mol}$ (range: $6100-18400$ ) for the patients and $11900 \mathrm{MBq} / \mu \mathrm{mol}$ (range: 6900-22 500) for the normal subjects.

Serial absences were induced by voluntary hyperventilation between 30 and 40 minutes after tracer injection in five patients and between 40 and 50 minutes post-injection in three others. The eight normal volunteers hyperventilated between 30 and 40 minutes post-injection. The arterial $\mathrm{pCO}_{2}$ was mea- sured at 20 minute post-injection and one minute before the end of hyperventilation.

Continuous arterial blood sampling to measure radioactivity was carried out at a rate of $5 \mathrm{ml}$ per minute for the first 10 minutes and then $2.5 \mathrm{ml}$ per minute using an on line bismuth germanate detection system. The formation of diprenorphine metabolites was measured in arterial blood 5, 10, 20 and 45 minutes post-injection. ${ }^{22}$

\section{DATA ANALYSIS}

${ }^{11} \mathrm{C}$-Diprenorphine scans were analysed with interactive image analysis software (Analyze version 3.0, Biodynamics Research Unit, Mayo Foundation, Rochester, MN, USA) on Sun 3/60 workstations (Sun Microsystem Inc, Mountain View, CA, USA). The AC-PC line was defined on an image of the distribution of radioactivity integrated from $30-90 \mathrm{~min}$ post-injection. ${ }^{23}$ In all subjects pitch and roll relative to this line were under three degrees, so reformatting of transaxial scans was not necessary. Images of the distribution of radioactivity integrated for the periods 10-30 minutes and 70-90 minutes were overlaid as a further check for subject movement during a scan. Two out of 10 patients scanned showed significant movement $(>3 \mathrm{~mm})$ and were therefore excluded from further analysis. A template of 155 rectangular regions of interest, average size of $1.2 \times 1.2 \mathrm{~cm}$, was adapted to the individual brain scans by visual inspection with reference to the stereotactic atlas of Talairach and Tournoux, ${ }^{24}$ using an integrated image of ${ }^{11} \mathrm{C}$-diprenorphine related radioactivity collected from 30 to 90 minutes (fig 1). The regions of interest template was placed on the following regions (the number of $7 \mathrm{~mm}$ transaxial planes contributing to each region are indicated in parentheses): brainstem (six), thalamus (two), caudate (three), putamen (three), cerebellum (four), anterior (six) and posterior (five) cingulate gyrus, frontal (eight), sensorimotor (five), medial (three) and lateral (five) temporal, parietal (five) and occipital neocortex (three). Time-activity curves, corrected for the physical decay of ${ }^{11} \mathrm{C}$, were constructed for individual regions of interest and curves of those regions belonging to each of the 13 predefined anatomical regions were combined and averaged. 


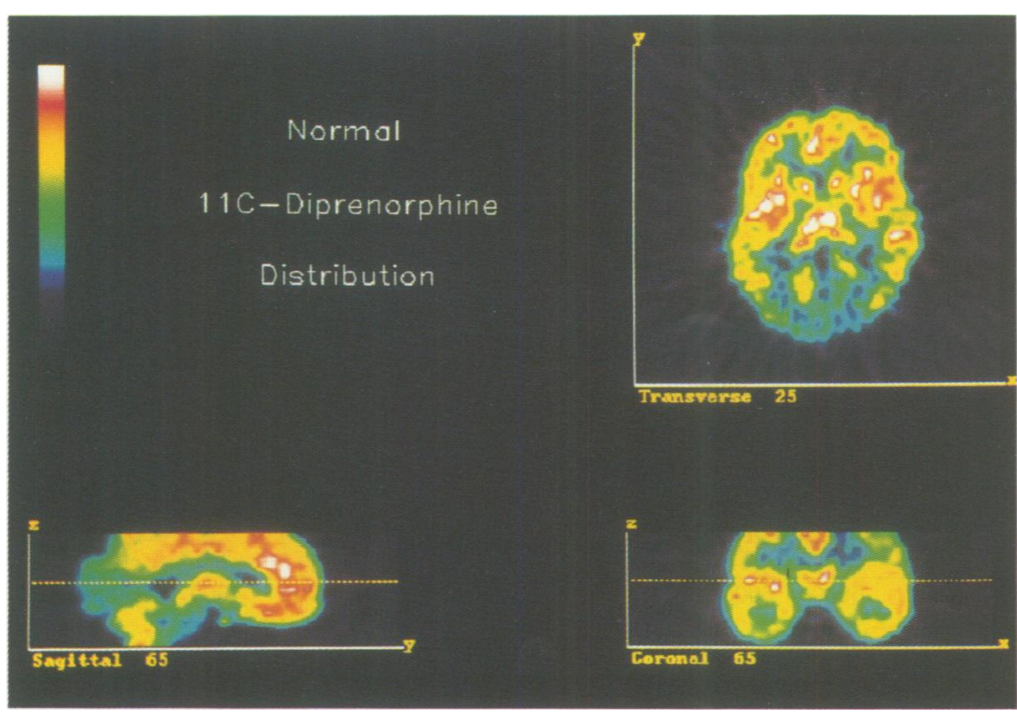

Figure 1 PET image showing regional distribution of ${ }^{11} C$-diprenorphine related radioactivity integrated from 30 to 90 minutes in a normal subject.

Analysis was in two parts. First, to control for the differences in injected radioactivity, the possibility of different volumes of tracer distribution in brain tissue, and for the differences in transport of tracer between plasma and cerebral extracellular space in different individuals, the decay-corrected regional time-activity curves were normalised to an amplitude of 100 over the period of 15-30 minutes post-injection. This period was chosen, as opposed to normalising to peak activity, as the time-activity tissue curve had flattened and so was less blood flow dependent, and also because it immediately preceded provocation by hyperventilation. The normalised tracer washout in the period from 60 to 90 minutes post-injection was then compared between all patients and normal subjects with analysis of variance.

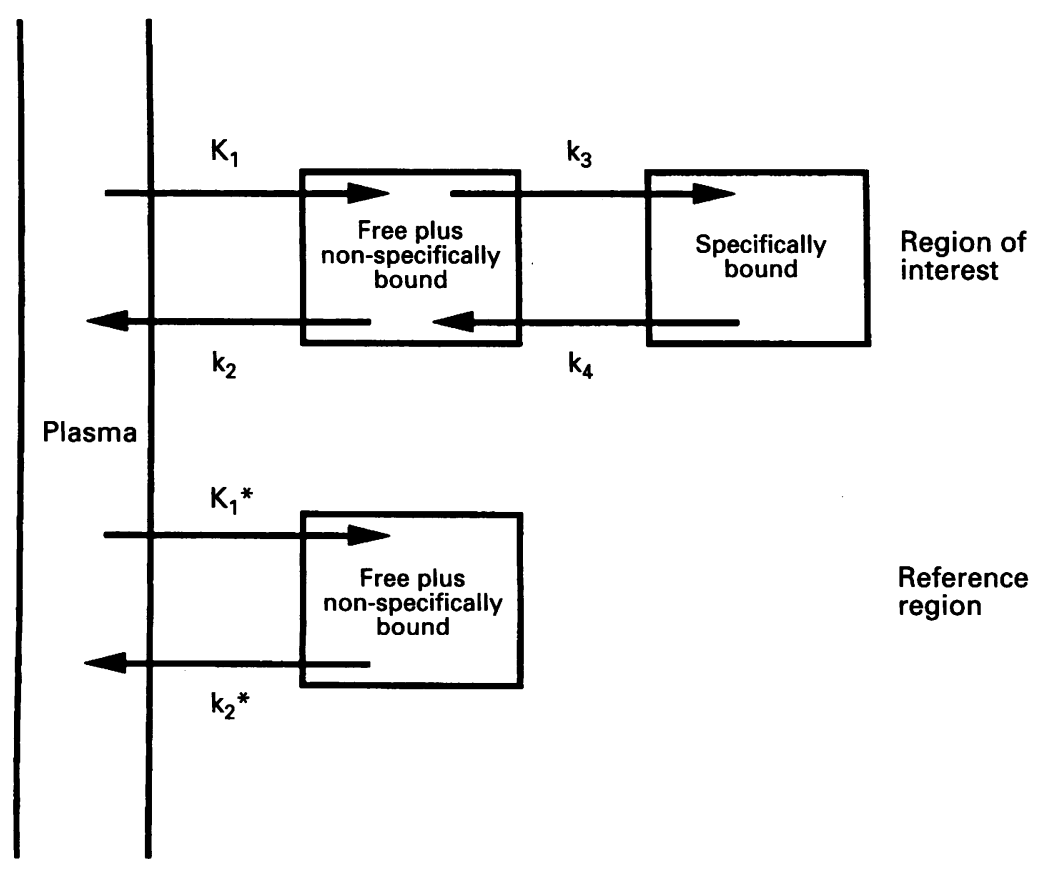

Figure 2 Two tissue compartment model incorporating a reference region and a region in which there are saturable binding sites for ${ }^{11} C$-diprenorphine. $k_{3}=f_{2} k_{o n}\left(B_{\max }-B\right) ; k_{4}=k_{o f f}$; binding potential $=k_{3} / k_{4} ; f_{2}=$ tissue free tracer fraction.
Secondly, a computed simulation was performed using the average time-activity curves of the five patients who hyperventilated from 30 to 40 minutes, comparing them with the averaged data of the eight normal subjects, using the primary visual cortex as reference tissue. Estimation of the extent of possible changes in the rate constants $\left(K_{1}, k_{2}, k_{3}\right.$ and $k_{4}$ ) during the period of hyperventilation was based on the reference tissue model described in detail by Cunningham et al (fig 2). ${ }^{2526}$ This model assumes that specific binding of the ligand is negligible in a reference region and that the ratio of the rate constants describing the transport of ligand between the vascular and tissue compartments is the same in a reference region $\left(K_{1} \star / k_{2}{ }^{\star}\right)$ as in a region in which specific binding occurs $\left(\mathrm{K}_{1} / \mathrm{k}_{2}\right)$. A nonlinear least mean squares fit of the tissue time-activity curves from the two regions was carried out on the averaged data of the normal subjects, in order to estimate the binding potential $\left(k_{3} / k_{4}\right)$.

The effects of changing the values of $K_{1}$, $k_{2}, k_{3}$ and $k_{4}$ for the duration of the 10 minute provocation period only, and also for the remainder of the study, on the shape of the computer-simulated curve were determined (fig 3), and the results compared with the fit of the tissue time-activity curves from the patients. In this way we sought to estimate the degree of change in the binding potential $\left(k_{3} / k_{4}\right)$ at the time of absence seizures and to test the robustness of this result in relation to possible changes in the other compartmental transfer constants. A decay and metabolite corrected arterial input function from a normal subject was used in the computed simulation; $\mathrm{K}_{1}=0.038$ per minute, $\mathrm{k}_{2}=0.096, \mathrm{k}_{3}$ $=0.3, k_{4}=0.06 . K_{1}$ and $k_{2}$ were calculated from the Renkin-Crone equation:

$K_{1}=$ flow $\left[1-e^{-P S i n f l o w}\right], k_{2}=$ flow [1- $\left.e^{-P S ~ o u t f l o w}\right]$. $\mathrm{PS}_{\text {in }}=0.6$ per minute, $\mathrm{PS}_{\mathrm{out}}=0.15$ per minute, in which PS $_{\text {in }}$ and PS $_{\text {out }}$ are the apparent permeability-surface area products for transfer of tracer across the blood-brain barrier.

\section{Results}

In all patients and normal subjects, the interictal $\mathrm{C}^{15} \mathrm{O}_{2}$-scan showed no focal abnormalities of cerebral perfusion. Serial absences were induced during the 10 minute period of hyperventilation in all patients. Generalised spike-wave discharges occupied between $10 \%$ and $51 \%$ (median $37 \%$ ) of the provocation period (table 1; fig 4). The amount of spontaneous spike-wave activity occurring between diprenorphine injection and provocation by hyperventilation was $0 \cdot 3-7 \cdot 0 \%$ (median $0 \cdot 7 \%$ ). The amount of spike-wave activity returned to the baseline rate over 1-5 minutes after the end of hyperventilation. The five patients restudied interictally, without hyperventilation, had spike-wave activity for $0 \cdot 2-5 \%$, median $1.5 \%$, of the duration of these scans. The EEGs of all control subjects were normal.

The rate of ${ }^{11} \mathrm{C}$-diprenorphine metabolism 
Figure 3 Simulated timeactivity curves for binding of ${ }^{11} \mathrm{C}$-diprenorphine to neocortex $\left(K_{1}=0.038\right.$ per minute, $k_{2}=0.096$ per minute, $k_{3}=0.3$ per minute, $k_{4}=0.06$ per minute). (a) Stable flow and binding constants (top curve) and effect of four-fold (centre curve) and 10-fold (bottom curve) increase in cerebral blood flow from 30 to 40 minutes (1800-2400s). (b) Effect of $0 \%, 20 \%$, $40 \%, 60 \%, 80 \%$ and

$100 \%$ reduction in $k_{3}$ from

30 minutes (1800 s), and continued to the end of the study. (c) Effect of $0 \%$, $20 \%, 40 \%, 60 \%, 80 \%$ and $100 \%$ reduction in $k_{3}$ from 30 minutes to 40 minutes only (1800-2400 s).
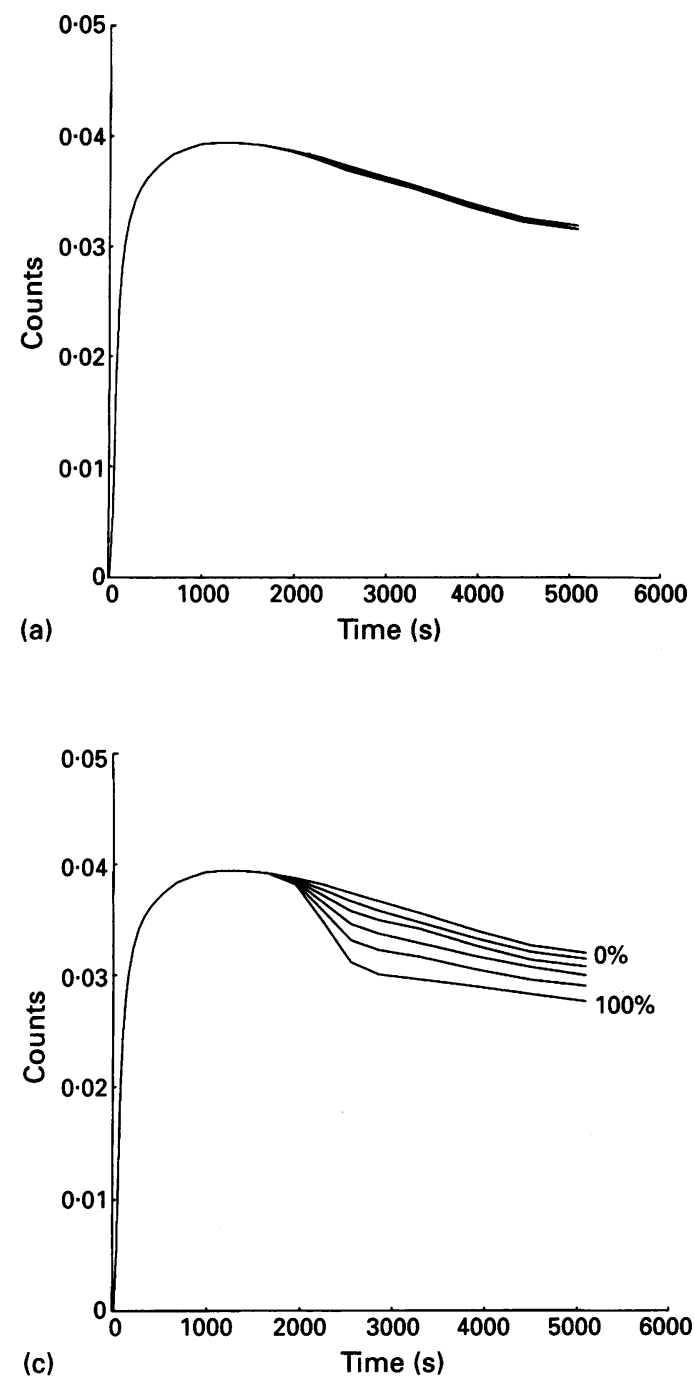

was similar in patients and normal subjects. Twenty minutes after injection the median percentage of unmetabolised ${ }^{11} \mathrm{C}$-diprenorphine in arterial blood was $43.3 \%$ (range: $18 \cdot 6-51 \cdot 1$ ) in the patients and $43.7 \%$ (range: $31 \cdot 9-57 \cdot 8$ ) in the normal subjects. The mean fall in arterial $\mathrm{pCO}_{2}$ after hyperventilation was $3.0 \mathrm{kPa}(\mathrm{SD} 1.1)$ in patients and $2.8 \mathrm{kPa}$ (SD 0.77 ) in control subjects.

Analysis of the normalised time activity

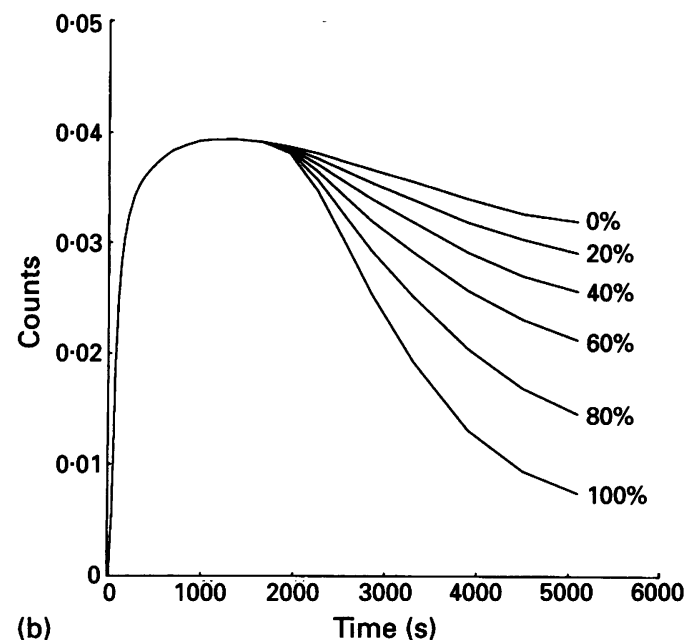

curves over $60-90$ minutes showed a greater clearance of radioactivity following hyperventilation induced serial absences from the brainstem $(p<0.01)$ and association neocortex (frontal, parietal, temporal) $(p=0.06)$, most marked in parietal cortex $(p<0.01)$ and posterior cingulate $(p<0.05)$, compared with normal subjects. There was no increase of tracer washout following serial absences in sensorimotor cortex, occipital cortex, thalamus, caudate, putamen, or cerebellum. There were no side to side differences of diprenorphine binding in regions in which time-activity curves of patients and control subjects did, and did not, diverge. There was no significant difference in time-activity curves before hyperventilation and in all cases the changes were noted after the onset of the flurries of absences (figs 5 and 6 ).

In the five patients who were studied with and without hyperventilation there was increased tracer washout following the provocation of serial absences from association neocortex (frontal, parietal, and temporal) ( $p$ $<\cdot 01$ ) (table 2, fig 6), with all areas showing a similar effect. There was no significant difference in tracer washout from the brainstem, or other brain areas, between the scans performed at rest and with provocation of absences. There was no appreciable difference in tracer washout from association cortex in controls and patients studied interictally (fig 6).

The extent of increased tracer washout in patients following hyperventilation was not correlated with the number or duration of absences provoked, the time taken for absences to subside to the baseline rate after the end of hyperventilation, the rate of diprenorphine metabolism, the severity or age of onset of epilepsy, age at time of study, or medication taken.

Comparison of normalised time-activity curves of the control subjects with normative data and simulated time-activity curves showed no increase in the loss of tracer after hyperventilation from any cerebral region. When the averaged time-activity curves of the five patients who hyperventilated from 30 to 40 minutes and the eight normal subjects 


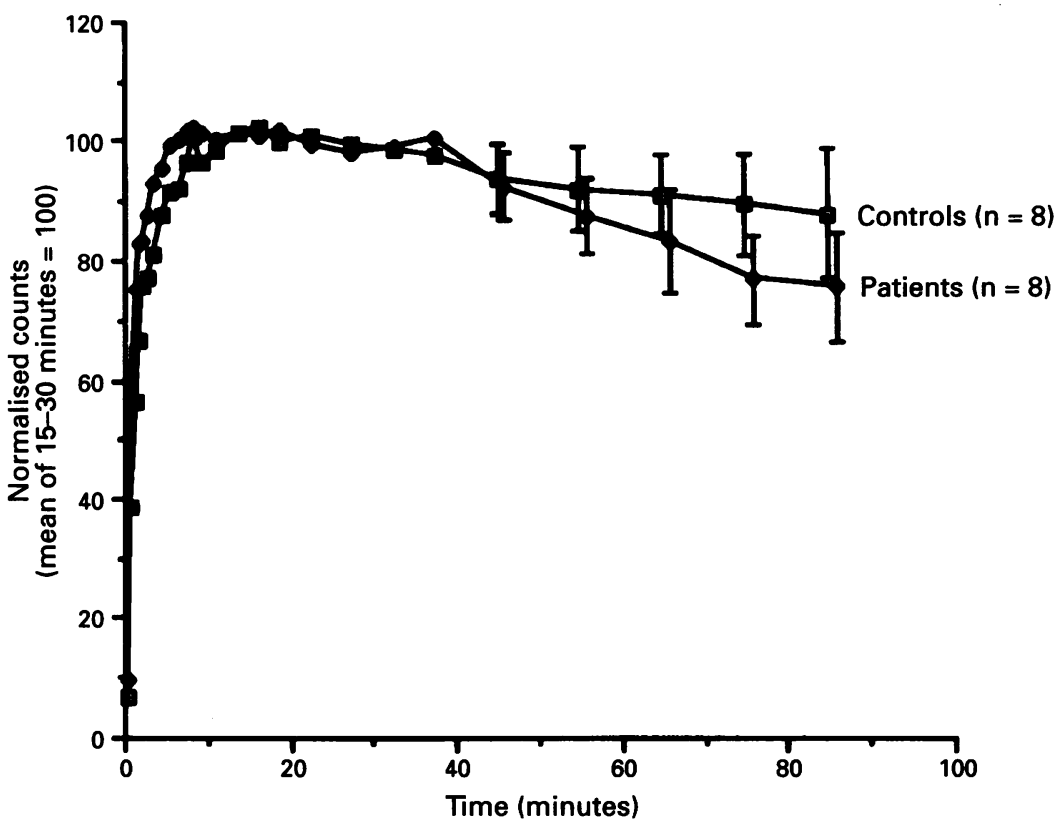

Figure 5 Example of normalized "C-diprenorphine kinetics (mean, SD) in parietal cortex showing effect of hyperventilation-induced absences at 30-50 minutes.

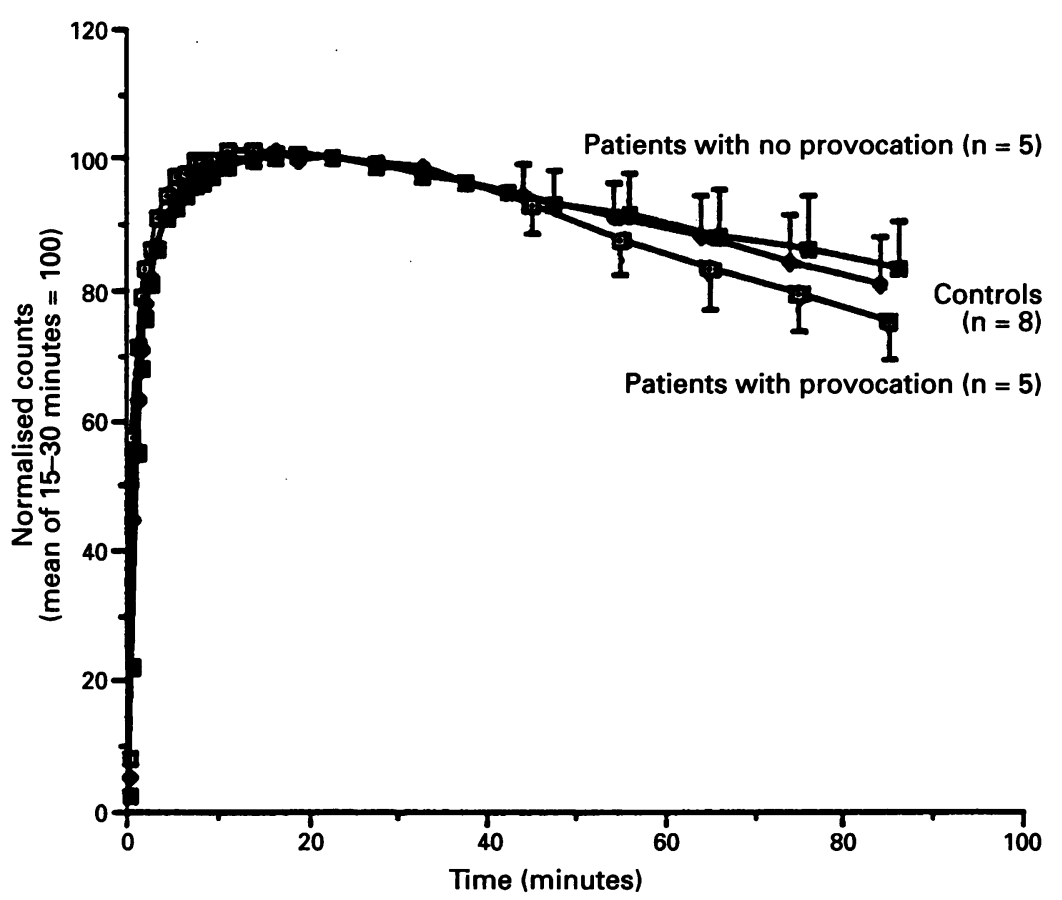

Figure 6 Normalized "C-diprenorphine kinetics (mean, SD) in association cortex (frontal, parietal, and temporal) of the eight control subjects, and showing effect of hyperventilation-induced absences at 30-40 minutes, in five patients studied with and without provocation of serial absences. were compared by computed simulation, it was estimated that, if a sustained decrease in $\mathrm{k}_{3}$ underlay the reduced diprenorphine retention seen in the patients, the extent of the fall was 41 (SD 15)\% in parietal cortex, 32 (SD $8.5) \%$ in posterior cingulate, 37 (SD 5.5)\% in lateral temporal cortex and 15 (SD 5)\% in frontal cortex. These results were the consequence of a simulated reduction in $k_{3}$ from the time of provocation of absences that was continued to the end of the study. If a transient fall in $k_{3}$, from 30 to 40 minutes only, was simulated, there was less effect on the simulated time-activity curves. The same endpoint, at 90 minutes, was reached by an $80 \%$ reduction of $\mathrm{k}_{3}$ from 30 to 40 minutes, and by a $20 \%$ reduction of $k_{3}$ that persisted from 30 to 90 minutes (figs $3 b, 3 c$ ). The essential parameter that is altered in this simulation is the binding potential $\left(k_{3} / k_{4}\right)$; doubling $k_{4}$ has an equivalent effect to halving $k_{3}$. Simulation of the effects of changes in cerebral blood flow showed that a four-fold and ten-fold increase in blood flow, from 30 to 40 minutes, had only minimal effects on the diprenorphine time-activity curve (fig 3a).

\section{Discussion}

The principal finding of this study was an increased loss of ${ }^{11} \mathrm{C}$-diprenorphine associated tissue radioactivity following serial absence seizure, from association cortex, compared with patients scanned interictally and hyperventilating control subjects. These observations suggest that the reduced tracer retention was associated with the flurry of absences in itself and was not a result of the condition of epilepsy or of hyperventilation. The effect was site selective. Thalamus, basal ganglia, cerebellum, occipital, and sensorimotor cortex did not show increased loss of ${ }^{11} \mathrm{C}$-diprenorphine signal after serial absences. Although there was reduced retention of ${ }^{11} \mathrm{C}$-diprenorphine in the brainstem of patients after serial absences compared with controls, there was no significant difference between patients studied with and without provocation of absences. In consequence no definite conclusions about changes in diprenorphine binding in the brainstem, in association with serial absences, can be drawn.

The divergence of the ictal and control time-activity curves appeared to follow the occurrence of serial absences, at $30-40$ and 40-50 minutes, and there was no evidence to suggest that this preceded the development of absences. The temporal resolution of the dynamic changes in diprenorphine binding was limited, however, and it was not possible to identify definite differences between the time-activity curves of patients who hyperventilated at $30-40$ or $40-50$ minutes. Further, absences occurred in flurries throughout the provocation period and signal to noise limitations precluded a more detailed temporal analysis of the dynamic changes in ${ }^{11} \mathrm{C}$-diprenorphine binding during this time.

In the patient group, the extent of increased diprenorphine washout after hyper- 
ventilation did not correlate with identified clinical factors (medication, age of onset, duration of epilepsy, occurrence of tonicclonic seizures), frequency of absences at baseline and on provocation. The basis of the variation in degree of response is uncertain and merits further investigation. This investigation was limited to subjects aged over 18 years by radiation protection regulations. The patients were highly selected, on the basis of having typical absences that had not remitted and which could be precipitated by hyperventilation. In consequence, it is not certain whether the results of this study could be extrapolated to apply to the generality of younger patients with childhood or juvenile absence epilepsy.

Great care was taken to eliminate the confounding effects of subject movement. Continuous EEG monitoring enabled precise quantification of the amount of spike-wave activity in the patients at the time of hyperventilation. No absences occurred during the central blood flow scans. Our data exclude differences in ${ }^{11} \mathrm{C}$-diprenorphine metabolism between patients and control subjects, and any effects of hyperventilation in themselves, as causes of the peri-ictally increased loss of tissue tracer in the patients. The quantities of the cold diprenorphine injected together with ${ }^{11} \mathrm{C}$-diprenorphine were always less than $0.3 \mu \mathrm{g} / \mathrm{kg}$, and this has been shown to have a negligible effect on receptor occupancy in vivo. ${ }^{26}$

The computed simulation, based on a two tissue compartment model, indicated that even a 10 -fold increase in cerebral blood flow at the time of provocation of absences would have only a marginal effect on the tracer kinetics and could not account for the observed ${ }^{11} \mathrm{C}$-diprenorphine washout during seizure activity. Further, the decreased ${ }^{11} \mathrm{C}$-diprenorphine binding after serial absences was site selective, whereas the increase in cerebral metabolism and blood flow that has been demonstrated during absences is diffuse and global, including caudate and thalamus. ${ }^{27}$

It seems likely that our observation of increased tracer washout after seizures was the consequence of a fall in binding potential for diprenorphine. In the cerebral areas in which peri-ictal changes were observed, the value of $k_{3}$ is about four to six times higher than the values of $k_{4}$ (fig 2). ${ }^{1826} \mathrm{~A}$ simulation with typical values of $k_{3}$ and $k_{4}$, showed that doubling $k_{4}$ had approximately the same effect on a simulated time-activity curve, as halving $k_{3}$. Our data suggest a fall in binding potential $\left(k_{3} / k_{4}\right)$ following serial absences but do not allow differentiation between changes in $k_{3}$, the specific tracer association rate constant, and $k_{4}$, the dissociation rate constant. The most likely explanation for our data is a fall in $k_{3}$ following serial absences, caused by a decrease in the number of opioid receptors available to bind labelled diprenorphine, rather than an increase in tracer dissociation $\left(k_{4}\right)$. Opioid receptors have a turnover time of the order of days, making it unlikely that changes in total receptor density are the explanation of our data. ${ }^{28}$ Release of endogenous opioids at the time of, and following absence seizures, which then compete with ${ }^{11} \mathrm{C}$-diprenorphine for specific binding sites would explain such a fall in $k_{3}$.

The extent of the observed changes indicates a marked biological effect. Complete arterial input curves were not available for all subjects, so the simulation was based on occipital cortex as a reference input function. The occiput has about $15 \%$ of the opioid receptor density of the average neocortex. ${ }^{18}$ Though this is comparatively small, it results in a slight overestimation of the changes in $\mathrm{k}_{3}$ in our computed simulation.

The computed simulations provided an estimate of the magnitude of the fall in binding potential that would explain the data. If binding potential was only reduced for the 10 minutes of the provocation period and then returned to baseline values, a much larger reduction of binding potential would be necessary to fit the experimental data than if the reduction of binding potential were maintained over the subsequent 60 minutes of the study (figs $3 \mathrm{~b}, 3 \mathrm{c}$ ). The gradual divergence of the control and postictal time-activity curves would favour a more modest reduction of binding potential that persists for the remaining 60 minutes of the scan, but our data do not exclude the possibility of a more marked short term effect. Our estimation of a 15 to $41 \%$ reduction in binding potential is of similar magnitude to the approximately $30 \%$ reduction of ${ }^{3} \mathrm{H}$-diprenorphine binding seen after depolarisation induced endogenous opioid release in hippocampal slices, and was similar to the $15-30 \%$ reduction in ${ }^{11} \mathrm{C}$-carfentanil binding in amygdala, temporal and cingulate cortex and thalamus found after electroconvulsive treatment and attributed to increased receptor occupation by endogenous opioids. ${ }^{1429}$ We suggest therefore that our data indicate the release of endogenous opioids at the time of serial absence seizures in the assocation areas of cerebral cortex, but not in thalamus, basal ganglia, or cerebellum. It is unclear whether diprenorphine binding in the brainstem is affected by serial absences.

The induction of absence-like seizures in rodents by enkephalins and prevention by ethosuximide, valproate and opiate antagonists suggest that enkephalins may have a role in the genesis of absences. ${ }^{10113}$ In contrast, the release of endogenous opioids, following convulsive seizures, has been suggested as a mechanism for suppressing further ictal activity. ${ }^{9123031}$ The patients we investigated did not have convulsions in the course of their PET studies. Although it is possible that endogenous opioid release may have been an epi-phenomenon to the provocation of serial absences, we speculate that these data indicate release of opioids, in vivo, that have a role in the pathophysiology of the absence seizures. There was no correlation between the number of absences provoked and the extent of reduced diprenorphine retention, suggesting the possibility that opioid release is 
one factor in a multifactorial process. The limited temporal resolution of the study does not allow determination of whether opioid release precedes, or is subsequent to, occurrence of absences, as these occurred in flurries over the 10 minute provocation period.

It is of note that we found evidence suggestive of endogenous opioid release in the cerebral cortex but not in the thalamus. Thalamocortical loops are implicated in the generation of absences ${ }^{34}$ and it is possible that the effects of endogenous opioids on this circuit are mediated through the association areas of the neocortex.

In a mouse model of generalised absence epilepsy, methionine enkephalin levels were increased in cortex, striatum, and brainstem, with no increase in $\beta$-endorphin or dynorphin levels, suggesting involvement of enkephalins in the pathophysiology of generalised absences. $^{32}$ It has not been established whether there are any persistent abnormalities of opioid receptor binding in generalised absence epilepsy. Further, the interrelationship between putative endogenous opioid release at the time of seizures and interictal receptor numbers is uncertain at present. The current study has not suggested a difference in cerebral diprenorphine binding between controls and patients, when serial absences are not provoked. Minor differences, however, cannot be excluded and the quantification of regional cerebral diprenorphine binding potential in patients with primary generalised epilepsy, interictally, is the subject of a continuing investigation.

In contrast, in patients with mesial temporal epileptic foci, a 35\% up-regulation of opioid binding to $\mu$-receptors has been found in overlying lateral temporal neocortex. ${ }^{33}$ In gerbils prone to generalised tonic-clonic seizures, the $B_{\max }$ (receptor density) of ${ }^{3} \mathrm{H}$-dihydromorphine binding was increased in substantia nigra, peri-aqueductal grey, and medial geniculate. ${ }^{34}$ These data suggest the possibility of tonic up-regulation of opioid neurotransmission that may be related to the pathogenesis of seizure susceptibility, or reflect homeostatic activation of an endogenous, antiepileptic mechanism at critical sites in subjects with partial and generalised tonicclonic seizures.

Diprenorphine is a non-selective opioid receptor ligand. ${ }^{19}$ Smaller doses of opioid peptides induce seizure activity than have analgesic effects and high doses of naloxone are required to block enkephalin-induced, absence-like seizures, implying involvement of non- $\mu$-receptors. ${ }^{1012} \delta$-Antagonists have been shown to block enkephalin-induced non-convulsive seizures. ${ }^{11}$ The relative importance of $\mu, \kappa$ and $\delta$ receptors, however, in the pathophysiology of different seizure types in vivo remains uncertain. ${ }^{123135}$ Further studies with more selective probes may identify which receptor subtypes are involved in the pathophysiology of epileptic seizures.

In conclusion, this study has produced some evidence for the release of endogenous opioids at the time of serial absence seizures in humans in the association areas of cerebral cortex, that may have an important role in the pathophysiology of absences.

We are grateful to the Medical Research Council, the Deutsche Forschungsgemeinschaft and to the MRCCyclotron unit staff, especially Professor Richard J S Frackowiak and Dr Terry Jones, for support and to Drs Frackowiak and Dr Terry Jones, for support and to Drs
Simon Shorvon and C P Panayiotopoulos for referring patients.

1 Meldrum BS. Historical introduction. In Meldrum BS, Ferendelli GA, Wieser HG, eds. Current problems in epilepsy, vol. 6: Anatomy of Epileptogenesis London: Libbey, 1988;1-13.

2 Engel J. Seizures and epilepsy. Philadelphia: FA Davies Company, 1989.

3 Gloor P. Generalized epilepsy with spike and wave discharge: a reinterpretation of its electrographic and clinicharge: a reinterpretation of its electrographic

4 Coulter DA, Huguenard JR, Prince DA. Differential effects of petit mal anticonvulsants and convulsants on thalamic neurones: calcium current reduction. $B r f$ Pharmacol 1990;100:800-6.

5 Tortella FC, Long JB. Endogenous anticonvulsant substance in rat CSF after a generalized seizure. Science 1985;228:1106-8.

6 Vindrola O, Briones R, Asai M, Fernandes-Guardiola A: Amygdaloid kindling enhances the enkephalin conten in the rat brain. Neurosci Lett 1981;21:39-43.

7 Hong JS, Wood PL, Gillin JC, et al. Changes of hippocampal metenkaphalin content after recurrent motor seizures. Nature 1980;285:231-2.

8 Green AR, Peralta E, Hong JS, et al. Alterations in GABA metabolism and met-enkephalin content in rat brain folmetabolism and met-enkephalin content in rat brain fol1978;31:607-11.

9 Bajorek JG, Lee RL, Lomax P. Neuropeptides: Anticonvulsant and convulsant mechanisms in epileptic model systems and in humans. Adv Neurol 1986; 44:489-500.

10 Snead OC, Bearden LJ. Anticonvulsants specific for petit mal antagonize epileptogenic effects of leucine enkephalin. Science 1980;210:1031-3.

11 Haffmans J, Dzoljic MR. Effects of delta opioid antagonists on enkephalin induced seizures. Pharmacology 1987;34:61-5.

12 Ramabadran K, Bansinath $M$. Endogenous opioid peptides and epilepsy. Int $f$ Clin Pharmacol Ther Toxicol 1990;28:47-62.

13 Frey $\mathrm{HH}$, Voits $\mathrm{M}$. Effect of psychotropic agents on a model of absence epilepsy in rats. Neuropharmacology 1991;30:651-6.

14 Neumaier JF, Chavkin C. Release of endogenous opioid peptides displaces ${ }^{3} \mathrm{H}$-diprenorphine binding in rat hippocampal slices. Brain Res 1989;493:292-302.

15 Jones AKP, Luthra SK, Maziere B, et al. Regional cerebral opioid receptor studies with "C-diprenorphine in normal volunteers. $\mathcal{f}$ Neurosci Methods 1988;23:121-9.

16 Frost J, Dannals RF, Duelfer T, et al. In vivo studies of opiate receptors. Ann Neurol 1984;15(suppl):85-92.

17 Frost JJ, Mayberg HS, Meltzer CC, et al. Measurement of ${ }^{11} \mathrm{C}$-carfentanil and "C-diprenorphine binding to opiate C-carfentanil and ${ }^{11} \mathrm{C}$-diprenorphine binding to opiate
receptors in man by PET. $\mathcal{f}$ Cereb Blood Flow Metab receptors in man

18 Sadzot B, Price JC, Mayberg HS, et al. Quantification of human opiate receptor concentration and affinity using high and low specific activity ${ }^{11} \mathrm{C}$-diprenorphine and positron emission tomography. F Cereb Blood Flow Metab 1991;11:204-19.

19 Richards ML, Sadee W. In vivo opiate receptor binding of oripavines to $\mu, \delta$ and $\kappa$ sites in rat brain as determined by an ex vivo labeling method. Eur $f$ Pharmacol 1985;114:343-53.

20 Spinks TJ, Jones T, Gilardi MC, Heather JD. Physical performance of the latest generation of commercial positron scanner. IEEE Trans Nucl Sci 1988;35:721-5.

21 Luthra SK, Turton DR, Dowsett $\mathrm{K}$, et al. Improved and automated 'one pot' radiosynthesis of "C-diprenorphine automated 'one pot' radiosynthesis of " ${ }^{11} \mathrm{C}$-diprenorphine 1991;30:258.

22 Luthra SK, Turton DR, Price G. The determination of unchanged "C-diprenorphine, "C-L-deprenyl and " $\mathrm{C}$ raclopride in plasma by HPLC. $f$ Label Compd Radiopharm 1991;30:378-9.

23 Friston KJ, Passingham RE, Nutt JG, Heather JD, Sawle GV, Frackowiak RSJ. Localisation in PET images: Direct fitting of the intercommisural (AC-PC) line. f Cereb Blood Flow Metab 1989;9:690-5.

24 Talairach J, Tournoux P. Coplanar stereotactic atlas of the human brain. New York: Georg Thieme Verlag, 1988.

25 Cunningham VJ, Fujiwara T, Luthra SK, et al. A procedure and compartmental analysis for measuring cerebral kinetics of ${ }^{11} \mathrm{C}$-diprenorphine in man. 7 Cereb Blood Flow Metab 1991;11(suppl. 2):S619.

26 Cunningham VJ, Hume SP, Price GR, et al. Compartmental analysis of diprenorphine binding to opiate receptors in the rat in vivo and its comparison opiate receptors in the rat in vivo and its comparison
with equilibrium data in vitro. $f$ Cereb Blood Flow Metab with equilibri

27 Theodore WH, Brooks R, Margolin R, et al. Positron emission tomography in generalised seizures. Neurology 1985;35:684-90. 
28 Simatov R, Lotem J, Levy R. Selectivity in the control of opiate receptor density in the animal and in cultured fetal brain cells. Neuropeptides 1984;5:197-200.

29 Frost J, Mayberg HS, Douglass KH, et al. Alteration of cerebral mu-opiate receptors in temporal lobe epilepsy and following ECT. 7 Cereb Blood Flow Metab 1987;7(suppl. 1):421.

30 Tortella FC, Cowan A. Studies on the role of opioid peptides as endogenous anticonvulsants. Life 1982;31: tides as

31 Tortella FC. Endogenous opioid peptides and epilepsy: quieting the seizing brain. Trends Pharmacol Sci 1988;9:366-72.
32 Patel VK, Abbott LC, Rattan AK, Tejwani GA. Increased methionine-enkephalin levels in genetically epileptic (tg/tg) mice. Brain Res Bull 1991;27:849-52.

33 Mayberg HS, Sadzot B, Meltzer CC, et al. Quantification of $\mathrm{Mu}$ and non-Mu opiate receptors in temporal lobe Neurol 1991;30:3-11.

34 Lee RJ, McCabe RT, Wamsley JK, et al. Opioid receptor alterations in a genetic model of generalised epilepsy. Brain Res 1986:380:76-82.

35 Jackson HC, Nutt DJ. Differential effects of selective $\mu$-, $\kappa$ - and $\delta$-opioid antagonists on electroshock seizure threshold in mice. Psychopharmacology 1991;103:380-3.
Early descriptions of sleep paralysis

Binns is usually credited with the first report in 1842 of paralysis which occurred in a daytime nap ${ }^{1}$ : hence his term "daymares": "utter incapacity for motion or speech, difficult respirations, and extreme dread".

The report by Binns establishes sleep paralysis in the absence of Gélineau's narcolepsy; ${ }^{2}$ this association was unrecognised until Levin ${ }^{3}$ identified 16 cases amongst 200 cases of narcolepsy in the literature up to 1933. Weir Mitchell ${ }^{4}$ in 1876 noted its occurrence as "nocturnal paralysis" in people who were emotionally and physically healthy.

Macnish ${ }^{5}$ in a scholarly account of sleep in 1834, may have depicted sleep paralysis in a nightmare: "At one moment he may have the consciousness of a malignant demon at his side; then to shun the sight of so appalling an object, he will close his eyes, but still the fearful being makes its presence known ... . if he looks up he beholds horrid eyes glaring upon him and an aspect of hell grinning at him ... Or, he may have the idea of a monstrous hag squatted upon his breast - mute, motionless and malignant." [my italics].

Macnish may have known Henry Fuseli's celebrated picture (The Nightmare 1781) which shows a demoniacal creature squatting on the chest and belly of a supine woman, apparently trying to rise from her bed; this has been pronounced by Schneck as an example of sleep paralysis.

Kinnier Wilson ${ }^{6}$ first introduced the term sleep paralysis for attacks precipitated by a terrifying dream. In Modern Problems in Neurology ${ }^{7}$ he described a 26 year old bricklayer with typical narcolepsy ( $v \alpha \rho \chi \eta$, numb, torpor) and cataplexy ( $\chi a \tau a \pi \lambda \eta \sigma \sigma \omega$, to strike down). Attacks of "tonelessness" occurred: "Of the greatest interest is the fact that when he has been asleep and dreaming, the emotional content of the dream has precipitated an attack of powerlessness . . . He was dreaming of a murder . . . he at once awoke and was fully conscious but was unable to move a single finger ... could not make a sound; the more he tried the more intense became his emotion and the more absolute his helplessness; he lay thus, flat on the floor, motionless but suffering acute mental distress, for some fifteen minutes ere the attack dissolved itself spontaneously ... Dr MacDonald Critchley, Registrar (sic) ... helped materially in the examination ... the first neurological examination of a patient in the cataplectic state."

J M S PEARCE

1 Binns E. The anatomy of sleep; or, the art of procuring sound and refreshing slumber at will. London: I Churchill, 1842. (Cited by Bell CC, et al, $\mathcal{F}$ Natl Med Assoc 1984, 76:501-8)

2 Gélineau J. De la narcolepsie. Gaz Hôp Paris 1880 53:626-8.

3 Levin $M$. The pathogenesis of narcolepsy, with a consideration of sleep paralysis and localized sleep. $f$ Neurol Pyychopathol 1933;14:1-13.

4 Mitchell SW. On some of the disorders of sleep. Virginia Med Monthly 1876;2:769-81. (Cited by Lindsley JG. Med Monthly 1876;2:769-81. (Cited by Lindsley JG. Sleep paralysis. In: Joseph AB, Young RR, eds. Movement disorders in neurology and

5 Macnish R. The philosophy of sleep. New York: Appleton, 1834

6 Wilson SAK. The narcolepsies. Brain 1928;51:63-109.

7 Wilson SAK. The narcolepsies. In: Modern problems in neurology. London: Edward Amold, 1928:82-4. 